\title{
Beneficial effects of Nadisudhi pranayama on reaction time
}

\author{
G. Sivagami ${ }^{1, *}$, Milind V Bhutkar ${ }^{2}$ \\ ${ }^{1}$ Assistant Professor, ${ }^{2}$ Professor \& HOD, Dept. of Physiology, Vinayaka Mission Kirupananda Variyar Medical College, Salem, \\ Tamil Nadu, India \\ *Corresponding Author: G. Sivagami \\ Email: sgshivudr164@gmail.com
}

Received: $7^{\text {th }}$ March, 2018

Accepted: $12^{\text {th }}$ July, 2018

\begin{abstract}
Introduction: Yoga is a technique which improves physical and mental health.Yoga unites the body and mind. Nadisudhi pranayama is one type of yoga; on regular practice it causes feeling of freshness, energy and lightness of body and mind.

Aim and Objectives: The study was designed to assess the beneficial effects of Nadisudhi pranayama on reaction time.

Materials and Methods: 60 young healthy subjects in the age group of 17-24 years were selected for the study. They received Nadisudhi pranayama training of 6 days a week for 6 weeks. Auditory reaction time \& visual reaction time were recorded before and after 6 weeks of training.

Results: Results were analyzed by using paired ' $t$ ' test. There was significant decrease in auditory\& visual reaction time after practice of Nadisudhi pranayama which signify a more alert state as well as improved central neural processing in Nadisudhi pranayama trained persons.

Conclusion: Nadisudhi pranayama is effective in decrease the reaction time. So Nadisudhi pranayama training may be beneficial to reduce the stress and improve the concentration.
\end{abstract}

Keywords: Nadisudhi pranayama, Auditory reaction time, Visual reaction time.

\section{Introduction}

Yoga is a science practiced in India over thousands of years. It is one of the best lifestyle modification ever devised in the history of mankind. Special and specific breathing technique called pranayama which produces many systemic psychophysical effects in the body besides its specific effects on respiratory functions. Nadishudhi pranayama helps to maintain balance between the Nadis. According to ancient yoga literature, 'Nadi' refers to a channel which flows energy within a body. Regular practice of Nadishudhi Prayanama improves the concentration power and ability to ignore and/or inhibit extraneous stimuli. Pranayamic practitioners are known to have better attention and less distractibility. ${ }^{1}$

Reaction time is the time interval between the application of stimulus and the beginning of appropriate voluntary response under the condition that the subject has been instructed to respond as rapidly as possible. ${ }^{2}$ It indicates the time taken by an individual to react to external stimulus. ${ }^{3}$ Reaction time is used to judge the ability of the person to concentrate and coordinate. It provides an indirect index of the integrity and processing ability of the central nervous system. ${ }^{4}$ It is a simple, non-invasive means of determining sensorimotor co-ordination and performance of an individual. $^{5}$

In previous studies, various parameters have been studied in yoga and pranayama practitioners. Various studies proved that beneficial effect of long-term pranayama techniques in the human body. This study was designed to know the effect of 6 weeks of
Nadisudhi pranayama practice on reaction time parameters in young healthy subjects.

\section{Aims and Objectives}

The aim of this study is to know the effects of 'Nadisudhi' Pranayama practice on visual \& auditory reaction time in young healthy subjects.

Objectives of the study are 1) To determine the reaction time (visual and auditory reaction time) before pranayama and after pranayama 2) To compare the reaction time (visual and auditory reaction time) before and after 6 weeks of pranayama practice and 3) To provide the scientific explanation for the difference.

\section{Materials and Methods}

The study group consists of 60 young healthy people from Vinayaka Mission Kirupananda Variyar Medical College, Salem, in the age group 17-24 years. Written informed consent was taken from all the subjects. They were trained in Nadisudhi pranayama for 6 weeks. They were trained for 30 minutes a day in the evening time at $4.30 \mathrm{pm}$ for six days per week. All of them followed balanced vegetarian diet. The first phase of recording of reaction time parameters was done at the beginning of the study. The second phase of recording was done after 6 weeks of regular nadisudhi pranayama practice.

Inclusion Criteria: Young healthy subjects aged between 17-24 years who were untrained in yoga previously.

Exclusion Criteria: The subjects with history of allergic disorders, respiratory disorders, Smoking, alcohol intake, Systemic disease like Diabetes, 
Hypertension, other cardiovascular disorders, Collagen disorders; Acute illness, Hearing disorder, Visual disorders were excluded from the study. Systemic disease and respiratory disorders were ruled out by history and clinical examination.

\section{Parameters Studied:}

1. Auditory reaction time(ART)

2. Visual reaction time (VRT)

Reaction Time: Reaction time was measured by PC 1000 Hertz Reaction Timer. Both visual \& auditory reaction times were recorded before 6 week of Nadisudhi pranayama training and after 6 weeks training of nadisudhi pranayama practice.

PC 1000 Hertz Reaction Timer: We used PC 1000 to measure auditory and visual reaction time which is an in house built add on device. ${ }^{6}$ PC 1000 is a 1000 hertz square wave oscillator which has two components (A \&B) connected to each other.

Component (A) has a start button which will be handled by the examiner only. Component (B) has a stop button which will be handled by the subject alone and also it has a small red LED and head phone (1000 hertz's tone) which receives the visual and auditory stimulus respectively. Component $\mathrm{A}$ and $\mathrm{B}$ are in turn connected to a personal computer which has audacity software installed in it. Audacity software records the reaction time in $0.001 \mathrm{sec}$ accuracy in wave format.

Recording of Visual Reaction Time (VRT) \& Auditory Reaction Time (ART): Once the examiner presses the start button in component $\mathrm{A}$, the subjects were instructed to press the STOP button in component $\mathrm{B}$ as soon as he/she sees the red light in the instrument or he/she hears the sound (1000 hertz's tone) through the headphone for recording Visual and auditory reaction time respectively. Visual or auditory reaction time was recorded in audacity software. During the recording of reaction times; component $\mathrm{A}$ was out of the view of the subject. ${ }^{7}$

Minimum five trials were given for both VRT and ART measurement. Minimum time recorded was calculated as final VRT and ART.

\section{Results and Analysis}

Descriptive statistical analysis has been carried out in the present study. Results are presented as Mean \pm SD. Student paired ' $t$ ' test was used to compare the differences in reaction time before \& after 6 weeks of Nadisudhi pranayama. Significance is assessed at $5 \%$ level of significance.

Table 1: Comparison of effect of 6 weeks Nadisudhi pranayama on reaction time parameters

\begin{tabular}{|c|c|c|c|}
\hline Variables & Before Pranayama & After Pranayama & p value \\
\hline ART $(\mathrm{m} \mathrm{sec})$ & $185.91 \pm 2.149$ & $154.33 \pm 2.297$ & $<0.0001$ \\
\hline VRT $(\mathrm{m} \mathrm{sec})$ & $222.7 \pm 2.345$ & $165.23 \pm 1.807$ & $<0.0001$ \\
\hline
\end{tabular}

As shown in Table 1, auditory reaction time (ART) - before pranayama was $185.91 \pm 2.14$ \& after pranayama was $154.33 \pm 2.297$. Auditory reaction time decreased after pranayama which is statistically significant $(\mathrm{P}<0.001)$.

As shown in Table 1, Visual reaction time (VRT) before pranayama was $222.7 \pm 2.345 \&$ after pranayama was $165.23 \pm 1.807$. Visual reaction time decreased after pranayama which is statistically significant $(\mathrm{P}<0.001)$.

\section{Discussion}

Yoga calms and relaxes the mind; strengthens as well as tunes the body and brings body and mind into harmony with one another". Yogic breathing technique pranayama is very important in inducing relaxation. Nadisudhi pranayama is the type pranayama, when performed regularly it has benefits on the various systems (respiratory system, cardiovascular system, central nervous system, etc.) of the body.

Visual \& auditory reaction time in pranayama practitioners found to be significantly decreased as shown in table 1. These results were consistent with previous studies done by Borker et al, ${ }^{1}$ Madanmohan et $\mathrm{al},{ }^{8}$ Malathi et al, ${ }^{9}$ Bhavanani et al. ${ }^{12}$

Borker et al trained the subjects in Pranayama breathing for 4 weeks and showed the result of decrease in auditory \& visual reaction time; where as in our study with 6 weeks of pranayama practice decreased the auditory \& visual reaction time. ${ }^{1}$

A study conducted by Madanmohan et al has shown that significant reduction in ART as well as VRT after 12 weeks training of various yogic techniques including Nadisudhi pranayama. ${ }^{8}$

Malathi et al have reported that significant reduction in auditory \& visual reaction time in Group-A had done 1 hour of yogasanas including pranayama as well as in Group B trained for 6 weeks of yogasanas including pranayama. ${ }^{9}$ Our results are in agreement with this study.

All these studies have reported that, decrease in visual $\&$ auditory reaction times in pranayama trained person could be due to an improvement in sensorimotor performance and central nervous system processing ability. This in turn could be due to an improved concentration power and ability to ignore extraneous stimuli. ${ }^{1,8}$ During pranayama, the subject are not only try to breathe but they also emphasized to keep concentrate on breathing. This stress free state of mind evokes relaxed responses. In this relaxed state, parasympathetic nerve activity overrides sympathetic nerve activity. ${ }^{10,11}$ This causes subject to ignore extraneous stimuli and improve the concentration power \& ability. ${ }^{1,8}$ So Yoga practitioners are known to 
have better attention and less distractibility which causes better performance and decrease in reaction time. ${ }^{8}$

Bhavanani et al conducted a study in which they compared the effect of asan, pranayama and combination of asan as well as pranayama training on reaction time, EEG \& other parameters. There was increase in beta, theta, and total power of EEG; decrease in ART in pranayama trainees which signifies more alert state in pranayama trainees. In asanpranayama trainees; there was increase in alpha, theta, total power as well as delta \% in EEG and decrease in reaction times (ART, VRT) which signifies an alert as well as relaxed state of the neuromuscular system. They have reported that yoga causes alertness at the same time relaxes the mind evidenced by synchronization of EEG waves and brain potentials. This in turn causes improvement in central neural processing and decrease in reaction time. ${ }^{12}$

Reaction time is the experiment which is related to alpha wave frequency and also to the level of arousal. ${ }^{13,14}$ It has been stated that RT will be faster with an intermediate level of arousal and RT will be decreased if the subjects are either too relaxed or too tensed. ${ }^{14}$ Earlier studies in yogis have shown persistent of EEG alpha waves with increase in amplitude during yoga has been demonstrated by Anand et al. ${ }^{15}$

Reaction time is an indirect index of processing capability of CNS which in turn affected by the instinctual status, mental status, instinctual and intellectual development. ${ }^{16}$ Pranayama synchronizes the logical and intuitive function by improving the coherence between two cerebral hemispheres. This increases alertness at the same it induces the relaxation, improves attention and concentration. Alertness decreases the reaction time of brain. ${ }^{17}$

So pranayama practice can probably affect central neural processing, increasing the alertness, arousal along with relaxation by synchronizing EEG waves and improve the concentration by parasympathetic over activity. All these lead to reduction in reaction times.

\section{Conclusion}

The study showed statistically significant decrease in reaction time after 6 weeks of Nadisudhi pranayama practice. Shortening of auditory reaction time \& visual reaction time in Nadisudhi pranayama trained persons signifying a more alert state, improved central neural processing. Thus pranayama practice increases the attention, concentration of an individual. Yoga practice can be suggested for all people especially for the students; working persons to improve their concentration over their studies / work and also to reduce the stress \& relax the mind. By using noninvasive, cost effective method of reaction time we can indirectly access the central neural processing easily. Reaction time is a simple, portable \& rapid method for monitoring the beneficial effects of yoga training.

\section{References}

1. Borker AS, Pednekar JR. Effect of pranayam on visual and auditory reaction time. Indian J Physiol Pharmacol. 2003;47(2):229-230.

2. Teichner WH. Recent studies of simple reaction time. Psychol Bull. 1954;51(2):128-149.

3. Mishra N, Mahajan KK, Maini BK. Comparative study of visual and auditory reaction time of hands and feet in males and females. Ind J Physiol Pharmacol. 1985;29(4):213-218.

4. Lofthus G K. Sensory motor performance and limb preference. Percepts Motor Skills. 1981;52(3):688-693.

5. Das S, Gandhi A, Mondal S. Effect of Premenstrual stress on audiovisual reaction time and audiogram. Ind J Physio Pharmacol. 1997;41(1):67-70.

6. Niruba R, Maruthy K N. Assessment of Auditory and Visual Reaction Time in Type 2 Diabetics -A Case Control Study. Al Ameen J Med Sci. 2011;4(3):274 -279.

7. Sheela Joice P P, Gunasekaran R, Maruthy K N. Influence of Yoga on Audiovisual Reaction Time of Medical Students. JMSCR. 2015;3(11):8162-66.

8. Madanmohan, Thombre DP, Bharathi Balakumar, Nambinara Yanan TK, et al. Effect of yoga training on reaction time, respiratory endurance and muscle strength. Indian J Physiol Pharmacol. 1992;36(4):229-233.

9. Malathi A, Vidya G, Parulkar. Effect of yogasanas on the visual and auditory reaction time. Indian J Physiol Pharmacol. 1989;33(1):110-112.

10. Jore S B, Prathamesh Kamble, Bhutada T B, Patwardhan M S. Effect of Pranayama training on Audio-Visual Reaction Time. International $J$ of Healthcare \& Biomedical Research. 2013;2(1):35-37.

11. Subbalakshmi N K, Saxsena S K, Urmila, Urban J A. Immediate effect of Nadi-shodhana pranayama on some selected cardiorespiratory \& higher functions of brain. Thai Journal of Physiological Sciences. 2005;18(2):1016.

12. Ananda Balayogi Bhavanani, Gopal Krushna Pal, Kaviraja Udupa, Krishnamurthy N Madanmohan Trakroo. A comparative study of the effects of asan, pranayama and asan-pranayama training on neurological and neuromuscular functions of Pondicherry police trainees. Int J Yoga. 2013;6(2):96-103.

13. Surwillo WW. Frequency of "alpha" rhythm, reaction time and age. Nature. 1961;191:823-824.

14. Welford AT. Choice reaction time: Basic concepts. In: Welford AT, editors. Reaction Times. New York: Academic Press; 1980;73-128.

15. Anand BK, Chhina GS, Baldev Singh. Some aspects of encephalographic studies in yogis. Electroencephal and Clin Neurophysiol. 1961;13(3):456-457.

16. Manish Dhadse, Ameet Fadia. Effect of Anulom Vilom Pranayam on Visual Reaction Time in Young Adults of Indian Population. International Journal of Basic and Applied Physiology. 2013;2(1):57-62.

17. Varsha Gupta, Yogesh Singh, Bibhava Vikramaditya, Harpreet Singh. Immediate effect of Nadishodhna pranayam on some selected parameters of cardiorespiratory and mental efficiency. Journal of Current Trends in Clinical Medicine \& Laboratory Biochemistry. 2014;2(3):12-15.

How to cite this article: Sivagami G, Bhutkar M. V. Beneficial effects of Nadisudhi pranayama on reaction time. Indian $\mathrm{J}$ Clin Anat Physiol. 2018;5(4):488-490. 